\title{
Identification of Genetic Relationships Among Morus alba Genotypes Based on RAPD and ISSR Fingerprinting
}

\author{
Duraisamy Kalpana, Hyo Jung Cha, Tae Ki Choi and Yang Soo Lee* \\ Department of Forest Science and Technology, Institute of Agricultural Science and Technology, \\ Chonbuk National University, Jeonju 561-756, Korea
}

\begin{abstract}
Mulberries have importance in the sericulture industry as food for Bombyx mori, silkworm reared for its silk. Korean Morus alba have many cultivars and, for the protection of these cultivars and for utilization in plant-breeding programs, genetic information and the diversity among cultivars are essential. This study with 14 mulberry genotypes was undertaken using RAPD and ISSR fingerprinting to discover the genetic divergences between cultivars. Polymorphism rate among the cultivars produced by RAPD primer was found to be $64.48 \%$ and $66.29 \%$ relative to ISSR primer. The genetic relationships among the cultivars were identified using a dendrogram constructed with the UPGMA clustering method. Nei's method was used to calculate the genetic dissimilarity coefficients between each pair of genotypes, and the highest dissimilarity coefficient of 0.246 was exhibited between Suwon and Hwanggum cultivars. To determine the efficiency of each primer, a polymorphic index was calculated, and the robustness of the dendrogram was checked using cophenetic correlation coefficient. The results of this study can be utilized for the improvement of mulberry varieties in plant-breeding programs.
\end{abstract}

Key words - Polymorphism, Dendrogram, Polymorphic index, Cophenetic correlation

\section{Introduction}

Mulberry is a deciduous tree and is a typical East Asian genus found in tropical, subtropical, and temperate regions of the world (Sastry, 1984). The mulberry belongs to genus Morus, which has been classified into many species and subspecies, primarily based on the floral characteristics (Koidzumi, 1917; Hotta, 1954; Katsumata, 1972), while later studies by Hirano (1982) classified mulberry based on protein profiles. The earlier studies based on morphological and biochemical characteristics of mulberry showed a divergence of genotypes (Mala et al., 1997; Fotedar and Dandin, 1998; Vijayan et al., 1999).

At present, the mulberry is recognized to have 68 species, among which Morus alba is an important source of food for the silkworm Bombyx mori. In Korea, the mulberry is also cultivated for manufacture of many food products. The identification and characterization of the cultivar is first step for any fruit introduction and improvement program. The

*Corresponding author. E-mail : ysoolee@chonbuk.ac.kr information on genetic diversity of cultivars will also facilitate breeding efforts (Yonemoto et al., 2006).

There are many molecular techniques that can be used to analyze the cultivars, including Random Amplified Polymorphic DNA (RAPD), Restriction Fragment Length Polymorphism (RFLP), Sequence-Tagged Sites (STS), Simple Sequence Repeats (SSRs), Expressed Sequence Tags (ESTs), InterSimple Sequence Repeats (ISSRs), Amplified Fragment Length Polymorphism (AFLP), and Sequence-Related Amplified Polymorphism (SRAP) markers. Selection of molecular technique is based on simplicity and reproducibility of the marker. The markers used for genome mapping, markerassisted selection, phylogenetic studies, and crop conservation should be low cost, easy to use, and reliable (Bornett and Branchard, 2001).

The technical simplicity and speed of Randomly Amplified Polymorphic DNA (RAPD) marker method has resulted in its popularity (Ammiraju et al., 2001). Studies were conducted to determine the genetic relationships of cultivars in mulberries (Srivastava et al., 2004; Vijayan, 2003; Bhattacharya and Anand Ranade, 2001), in Dimocarpus longan (Yonemoto et 
al., 2006), and in Arachis hypogea (Raina et al., 2001) using the RAPD markers. The RAPD technique is used to elucidate the genetic diversity between related individuals (Williams et al., 1990; Welsh et al., 1990).

Inter-simple sequence repeats (ISSRs) have been introduced as molecular markers (Zietkiewicz et al., 1994) and are semi-arbitrary markers that emerged as an alternative technique based on the reliability and advantages of microsatellites and the broad taxonomic applications of RAPD (Ammiraju et al., 2001). Several studies have been conducted using ISSR markers to determine the genetic diversity among cultivars of rice (Blair et al., 1999; Wu and Tanksley, 1993), potato (Prevost et al., 1999) oilseed rape (Charters et al., 1996), corn (Kantety et al., 1995), safflower (Deepmala Sehgal and Soom Nath Raina, 2005), and citrus (Fang and Rose, 1997). In this current study, we used RAPD and ISSR markers to study the genetic relationships among the 14 mulberry genotypes grown in the Jeonju region of South Korea.

\section{Materials and Methods}

\section{Sample Collection}

Leaves from 14 selected mulberry genotypes (Morus alba L.) from the Sericultural Institute of Chonbuk, South Korea were collected and separately placed in air-lock packs and stored at $-80^{\circ} \mathrm{C}$ for DNA extraction. The names and accessions given to the 14 genotypes, morphological characters and leaf size are as presented in the table 1 .

\section{Isolation of genomic DNA}

Leaves were used for genomic DNA isolation using the method of Doyle and Doyle (1987), with some modifications. Ten milligrams of leaf sample was weighed and finely ground into a powder using liquid nitrogen in sterilized, clean Eppendorf tubes. Five hundred microliters of extraction buffer, prepared with $2 \%$ CTAB, $100 \mathrm{mM}$ Tris- $\mathrm{HCl}(\mathrm{pH}$ 8.0), 200 mM EDTA ( $\mathrm{pH} 8.0$ ), 1.4 M NaCl, 0.5\% $\beta$ mercaptoethanol, and 1.5\% PVP, was added and vortexed well. The tubes were incubated at $65^{\circ} \mathrm{C}$ in a water bath for 15 min with regular mixing of sample every $5 \mathrm{~min}$. After incubation, equal volumes of chloroform were added, and the tubes were gently inverted and mixed well. The centrifugation of the tubes was carried out at $4{ }^{\circ} \mathrm{C}$ for $10 \mathrm{~min}$ at $12,000 \mathrm{~g}$. Into the fresh tube, $500 \mu \mathrm{l}$ of aqueous layer was carefully transferred, followed by $500 \mu \mathrm{l}$ of cold 2-propanol. Centrifugation was again carried out at $12,000 \mathrm{~g}$ and $4{ }^{\circ} \mathrm{C}$ for $10 \mathrm{~min}$. The DNA was pelleted and washed twice with $70 \%$ ethanol. The washing was followed by air-drying and dissolution of DNA in $100 \mu \mathrm{l}$ of sterile Millipore water. The isolated DNA was quantified using $0.8 \%$ agarose gel electrophoresis, and the DNA was diluted to a uniform concentration of $10 \mathrm{ng} / \mu 1$ for RAPD and ISSR fingerprinting.

\section{PCR amplification of the DNA with RAPD primers}

The RAPD analyses were carried out using 40 primers, 20 primers from each OPA and OPY set. The names and the sequences of the primers utilized for the study are provided in Table 2. The PCR reactions were performed on the ESCO Swift Maxi ${ }^{\circledR}$ thermocycler under the following conditions: initial denaturation at $93^{\circ} \mathrm{C}$ for $5 \mathrm{~min}, 40$ cycles of denaturation at $93{ }^{\circ} \mathrm{C}$ for $30 \mathrm{sec}$, annealing at $36^{\circ} \mathrm{C}$ for $30 \mathrm{~min}$, and elongation at $72^{\circ} \mathrm{C}$ for $30 \mathrm{sec}$. The final extension was carried out at $72^{\circ} \mathrm{C}$ for $15 \mathrm{~min}$. The $30-\mu 1$ PCR mixture was set up with $1 X$ PCR buffer, $35 \mathrm{mM} \mathrm{MgCl} 2,10 \mathrm{ng}$ of genomic DNA, 20 pmoles of the primer, $10 \mathrm{mM}$ dNTPs consisting of $2.5 \mathrm{mM}$ each of dATP, dCTP, dGTP, and dTTP, and $1 \mathrm{U}$ of Taq polymerase. The PCR products were electrophoresed on a $1.2 \%$ agarose gel using $1 \mathrm{X}$ TAE buffer and subsequently stained with ethidium bromide. The gel image was photographed using the Gel Documentation System.

\section{PCR amplification of the DNA with ISSR primers}

Initially, 25 primers from UBC801-825 were tested and, of those, ten which yielded a good banding pattern and polymorphism rate were further used for the analysis. The PCR mixture contains $1 X$ PCR buffer, $35 \mathrm{mM} \mathrm{MgCl}_{2}, 10 \mathrm{ng}$ of genomic DNA, 20 pmoles of the primer, $10 \mathrm{mM}$ dNTPs consisting of $2.5 \mathrm{mM}$ each of dATP, dCTP, dGTP, and dTTP, and $1 \mathrm{U}$ of Taq polymerase, for a total reaction volume of $30 \mu 1$. The PCR conditions included an initial denaturation at $93{ }^{\circ} \mathrm{C}$ for $5 \mathrm{~min}$, followed by 40 cycles of $93^{\circ} \mathrm{C}$ for $30 \mathrm{sec}$, $60^{\circ} \mathrm{C}$ for $30 \mathrm{sec}$, and $72^{\circ} \mathrm{C}$ for $2 \mathrm{~min}$, and a final extension step at $72^{\circ} \mathrm{C}$ for $15 \mathrm{~min}$, after which the reaction was maintained at $4{ }^{\circ} \mathrm{C}$. Eight microliters of the PCR products were separated 
Table 1. List of the mulberry cultivars utilized, their accession number, morphological characters and leaf size.

\begin{tabular}{ccllcr}
\hline \hline $\begin{array}{c}\text { Given } \\
\text { accession No }\end{array}$ & $\begin{array}{c}\text { Name of the } \\
\text { cultivar }\end{array}$ & & \multicolumn{1}{c}{ Morphological characters } & Width & Length \\
\hline M1 & Suwon & Leaf oval-oblong, base cordate, margin 3-5 lobed, apex apiculate & $15.7 \pm 1.72$ & $20.3 \pm 2.16$ \\
M2 & Baeksaang & $\begin{array}{l}\text { Leaf ovate, base cordate, margin serrate, entired, apex acumilate } \\
\text { or apiculate }\end{array}$ & $12.7 \pm 2.11$ & $17.1 \pm 1.29$ \\
M3 & Suwonsang1ho & Leaf oval-oblong, base truncate, margin lobed 3-5, apex acuminate & $16.8 \pm 1.32$ & $18.05 \pm 0.60$ \\
M4 & Gakyongsang & Leaf ovate, base cordate, margin serrate, entired, apex acuminate & $13.6 \pm 1.51$ & $18.1 \pm 1.20$ \\
M5 & Sekang & Leaf ovate, base cordate, margin serrate, entired, apex acuminate & $10.15 \pm 2.93$ & $12.8 \pm 3.16$ \\
M6 & Guksang70ho & Leaf ovate, base cordate, margin serrate, entired, apex apiculate & $14.0 \pm 1.39$ & $16.05 \pm 1.61$ \\
or aristulate & Leaf ovate, base cordate, margin serrate, entired, apex apiculate & $9.35 \pm 0.75$ & $9.85 \pm 0.75$ \\
M7 & Hwanggum & Ilbongum & Leaf ovate, base sargitate, margin serrate, entired, apex apiculate & $19.6 \pm 0.97$ & $20.7 \pm 1.57$ \\
M9 & Mosam & Leaf ovate, base cordate, margin serrate, entired, apex aristulate & $17.2 \pm 1.87$ & $20.4 \pm 0.70$ \\
M10 & Jeonwon2ho & Leaf ovate, base cordate, margin serrate, entired, apex apiculate & $12.75 \pm 1.66$ & $16.85 \pm 1.48$ \\
M11 & Hyangsang & Leaf orbicular, base truncate, margin 8-10 lobed, apex apiculate & $16.45 \pm 0.96$ & $16.65 \pm 0.82$ \\
M12 & Hosam & Leaf ovate, base cordate, margin serrate, entired, apex apiculate & $13.1 \pm 2.73$ & $16.95 \pm 2.79$ \\
M13 & Jakchunil & Leaf ovate, base cordate, margin serrate, entired, apex apiculate & $13.1 \pm 1.02$ & $17.45 \pm 0.76$ \\
or aristulate & Leaf ovate, base cordate, margin serrate, entired, apex acute & $12.17 \pm 2.70$ & $16.88 \pm 2.98$ \\
\hline
\end{tabular}

Leaf size: Mean \pm standard error of ten representative samples.

on a $1.2 \%$ agarose gel, stained with ethidium bromide, and the bands were photographed.

\section{Scoring and data analysis}

The bands produced by each primer set were analyzed, with each band treated as a unit, and score of 1 was assigned to the presence of a band, while a score of 0 was given for the absence of a band. Bands were considered polymorphic if the amplified product was not present in at least one of the cultivars, whereas if the same band was present in all genotypes, it was considered to be monomorphic. The dissimilarity matrix and the dendrogram construction were performed using NTSyspc 2.11c (Numerical Taxonomy System). The Nei72 (Nei, 1972) method was used to construct the dissimilarity matrix, which

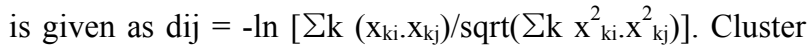
analysis was performed using the dissimilarity matrix and the UPGMA (Unweighted Pair Grouping Method using Arithmetic average) method. From the tree matrix, cophenetic matrix was computed, compared with the original dissimilarity matrix and the cophenetic correlation coefficient was calculated using Mantel's matrix correspondence test (Mantel, 1967). The multiplex ratio was calculated for each marker by dividing the total number of amplified bands (monomorphic and polymorphic) by the total number of assays (i.e., the primer combinations employed) as described by Powell et al.(1996).

The PIC (polymorphic index) of each marker was calculated using modified form of original formula $\mathrm{PIC}=1-\sum \mathrm{P}_{\mathrm{i}}{ }^{2}$, where $P_{i}$ is the band frequency of $i^{\text {th }}$ allele (Smith et al., 1997). For RAPD and ISSR markers, the PIC was calculated as $1-\mathrm{p}^{2}-\mathrm{q}^{2}$, where $\mathrm{p}$ is band frequency and $\mathrm{q}$ is no-band frequency (Ghislain et al., 1999). These PIC values were used to calculate the RAPD primer index and ISSR primer index, which are calculated by adding all of the PIC values of all of the markers amplified by the same primer (Raina et al., 2001). The average values were then calculated by dividing the number of markers produced by each primer.

\section{Results and Discussion}

\section{Morphological Character analysis}

Among the fourteen genotypes Suwon genotype was found to be medium flowering, leaves are of high quality and are used to feed the young silkworm larva, produced more fruits and freezing tolerance was quite strong. The common characters 
observed from majority of cultivars are ovate leaf with cordate base, serrate and entired margin and apiculate apex. The two cultivars Suwon and Suwonsang1ho had oval-oblong leaf and 3-5 lobed leaves. The morphology of Hyangsang was entirely different from all other 13 accessions; they had orbicular leaf with 8-10 lobes. The diversity analysis of cultivars using morphological characters was observed to be very difficult because the morphological characters were very similar between the genotypes, so the diversity analysis of genome was carried out using RAPD and ISSR fingerprinting.

\section{Polymorphism rate between the genotypes based on RAPD and ISSR markers}

A total of 50 primers were utilized for this study, 40 RAPD and ten ISSR primers, to determine the diversity among 14 Morus alba genotypes. All of the primers, with exceptions of OPY-12 and OPY-17, produced amplified products. The number of products varied between 1 and 15, and sizes of product varied from less than $500 \mathrm{bp}$ to $4000-5000 \mathrm{bp}$. The primers OPA-4, OPA-18, OPY-2, OPY-7, and OPY-8 produced a maximum of 15 bands, while the UBC- 817 primer produced

Table 2. Polymorphisms generated by RAPD primers among the 14 mulberry genotypes.

\begin{tabular}{|c|c|c|c|c|c|}
\hline Primer name & Sequence $5^{\prime}-3^{\prime}$ & $\%$ polymorphisms & Primer name & Sequence $\left(5^{\prime}-3^{\prime}\right)$ & \% polymorphisms \\
\hline OPA-01 & CAGGCCCTTC & 42.85 & OPY-01 & GTGGCATCTC & 57.14 \\
\hline OPA-02 & TGCCGAGCTG & 80 & OPY-02 & CATCGCCGCA & 60 \\
\hline OPA-03 & AGTCAGCCAC & 66.67 & OPY-03 & ACAGCCTGCT & 33.3 \\
\hline OPA-04 & AATCGGGCTG & 66.67 & OPY-04 & GGCTGCAATG & 46.15 \\
\hline OPA-05 & AGGGGTCTTG & 66.67 & OPY-05 & GGCTGCGACA & 57.14 \\
\hline OPA-06 & GGTCCCTGAC & 33.33 & OPY-06 & AAGGCTCACC & 25 \\
\hline OPA-07 & GAAACGGGTG & 83.33 & OPY-07 & AGAGCCGTCA & 53.33 \\
\hline OPA-08 & GTGACGTAGG & 77.78 & OPY-08 & AGGCAGAGCA & 53.33 \\
\hline OPA-09 & GGGTAACGCC & 55.55 & OPY-09 & AGCAGCGCAC & 55.55 \\
\hline OPA-10 & GTGATCGCAG & 87.5 & OPY-10 & CAAACGTGGG & 75 \\
\hline OPA-11 & CAATCGCCGT & 50 & OPY-11 & AGACGATGGG & 66.67 \\
\hline OPA-12 & TCGGCGATAG & 60 & OPY -12 & AAGCCTGCGA & 0 \\
\hline OPA-13 & CAGCACCCAC & 70 & OPY-13 & GGGTCTCGGT & 78.5 \\
\hline OPA-14 & TCTGTGCTGG & 0 & OPY-14 & GGTCGATCTG & 76.92 \\
\hline OPA-15 & TTCCGAACCC & 83.33 & OPY-15 & AGTCGCCCTT & 64.4 \\
\hline OPA-16 & AGCCAGCGAA & 87.5 & OPY-16 & GGGCCAATGT & 0 \\
\hline OPA-17 & GACCGCTTGT & 50 & OPY-17 & GACGTGGTGA & 0 \\
\hline OPA-18 & AGGTGACCGT & 66.67 & OPY-18 & GTGGAGTCAG & 28.57 \\
\hline OPA-19 & CAAACGTCGG & 71.42 & OPY-19 & TGAGGGTCCC & 88.89 \\
\hline OPA-20 & GTTGCGATCC & 83.33 & OPY-20 & AGCCGTGGAA & 85.71 \\
\hline
\end{tabular}

Table 3. Polymorphism generated by ISSR primers among the 14 mulberry genotypes.

\begin{tabular}{cccc}
\hline \hline Primer name & Sequence (5'-3') & \% GC content & \% polymorphisms \\
\hline UBC 807 & AGAGAGAGAGAGAGAGT & 47.1 & 70 \\
UBC 808 & AGAGAGAGAGAGAGAGC & 52.9 & 57.14 \\
UBC 809 & AGAGAGAGAGAGAGAGG & 52.9 & 50 \\
UBC 810 & GAGAGAGAGAGAGAGAT & 47.1 & 54.54 \\
UBC 814 & CTCTCTCTCTCTCTCTA & 47.1 & 80 \\
UBC 815 & CTCTCTCTCTCTCTCTG & 52.9 & 66.67 \\
UBC 817 & CACACACACACACACAA & 47.1 & 91.97 \\
UBC 820 & GTGTGTGTGTGTGTGTC & 52.9 & 60 \\
UBC 824 & TCTCTCTCTCTCTCTCG & 52.9 & 83.33 \\
UBC 825 & ACACACACACACACACT & 47.1 & 40 \\
\hline
\end{tabular}


a maximum of 12 bands. The polymorphism rates produced by each primer were calculated and are presented in Tables 2and 3. The primers OPA-7, OPA-10, OPA-15, OPA-16, OPA-20, OPY-19, and OPY-20 showed a high percentage of polymorphism of more than $80 \%$ among the genotypes tested. The primer OPA-14 produced one amplified band and no polymorphic bands were exhibited by this primer. The ISSR primer UBC-17 produced highest percentage of polymorphism
(91.97\%), followed by primer UBC-25 (83.33\%). The ISSR marker revealed a higher percentage of polymorphism $(66.29 \%)$ than did the RAPD marker $(64.48 \%)$. Our results showing a higher percentage of polymorphism are similar to the results from earlier studies on mulberries (Srivastava et al., 2004).

The application of a molecular marker technique for analysis depends on number of markers produced by each primer and

Table 4. Number of bands and sizes of products generated by the RAPD primers.

\begin{tabular}{|c|c|c|c|c|c|c|c|c|c|c|c|}
\hline \multirow[t]{2}{*}{ Primer name } & \multirow[t]{2}{*}{$\mathrm{NAB}^{\dagger}$} & \multirow[t]{2}{*}{$\mathrm{NMB}^{\ddagger}$} & \multirow[t]{2}{*}{$\mathrm{NPB}^{\S}$} & \multicolumn{2}{|c|}{$\begin{array}{l}\text { Size (kbp) of the } \\
\text { product }\end{array}$} & \multirow{2}{*}{$\begin{array}{c}\text { Primer } \\
\text { name }\end{array}$} & \multirow[t]{2}{*}{$\mathrm{NAB}^{\dagger}$} & \multirow[t]{2}{*}{$\mathrm{NMB}^{\ddagger}$} & \multirow[t]{2}{*}{$\mathrm{NPB}^{\S}$} & \multicolumn{2}{|c|}{$\begin{array}{l}\text { Size (kbp) of the } \\
\text { product }\end{array}$} \\
\hline & & & & Min & Max & & & & & Min & $\operatorname{Max}$ \\
\hline OPA-01 & 7 & 4 & 3 & $<0.5$ & $2.0-2.5$ & OPY-1 & 7 & 3 & 4 & $<0.5$ & $2.0-3.0$ \\
\hline OPA-02 & 10 & 2 & 8 & $0.5-1.0$ & $2.5-3.0$ & OPY-2 & 15 & 6 & 9 & $<0.5$ & $3.0-4.0$ \\
\hline OPA-03 & 12 & 4 & 8 & $<0.5$ & $2.5-3.0$ & OPY-3 & 3 & 2 & 1 & $1.0-2.0$ & $2.0-3.0$ \\
\hline OPA-04 & 15 & 5 & 10 & $<0.5$ & $2.5-3.0$ & OPY-4 & 13 & 7 & 6 & $<0.5$ & $2.0-3.0$ \\
\hline OPA-05 & 12 & 4 & 8 & $<0.5$ & $2.0-2.5$ & OPY-5 & 14 & 6 & 8 & $<0.5$ & $3.0-4.0$ \\
\hline OPA-06 & 3 & 2 & 1 & $0.5-1.0$ & $0.5-1.0$ & OPY-6 & 12 & 9 & 3 & $0.5-1.0$ & $2.0-3.0$ \\
\hline OPA-07 & 12 & 2 & 10 & $<0.5$ & $2.5-3.0$ & OPY-7 & 15 & 7 & 8 & $<0.5$ & $3.0-4.0$ \\
\hline OPA-08 & 9 & 2 & 7 & $<0.5$ & $2.0-2.5$ & OPY-8 & 15 & 7 & 8 & $<0.5$ & $2.0-3.0$ \\
\hline OPA-09 & 9 & 4 & 5 & $<0.5$ & $2.0-2.5$ & OPY-9 & 9 & 4 & 5 & $<0.5$ & $2.0-3.0$ \\
\hline OPA-10 & 8 & 1 & 7 & $<0.5$ & $1.0-1.5$ & OPY-10 & 8 & 2 & 6 & $<0.5$ & $1.0-2.0$ \\
\hline OPA-11 & 8 & 4 & 4 & $<0.5$ & $1.5-2.0$ & OPY-11 & 6 & 2 & 4 & $0.5-1.0$ & $2.0-3.0$ \\
\hline OPA-12 & 5 & 2 & 3 & $<0.5$ & $1.0-1.5$ & OPY-12 & 0 & 0 & 0 & 0 & 0 \\
\hline OPA-13 & 10 & 3 & 7 & $<0.5$ & $2.0-2.5$ & OPY-13 & 14 & 3 & 11 & $0.5-1.0$ & $3.0-4.0$ \\
\hline OPA-14 & 1 & 1 & 0 & $0.5-1.0$ & $0.5-1.0$ & OPY-14 & 10 & 3 & 7 & $0.5-1.0$ & $1.0-2.0$ \\
\hline OPA-15 & 6 & 1 & 5 & $1.0-2.0$ & $4.0-5.0$ & OPY-15 & 13 & 3 & 10 & $<0.5$ & $2.0-3.0$ \\
\hline OPA-16 & 8 & 1 & 7 & $0.5-1.0$ & $2.0-3.0$ & OPY-16 & 14 & 5 & 9 & $<0.5$ & $3.0-4.0$ \\
\hline OPA-17 & 6 & 3 & 3 & $0.5-1.0$ & $2.0-3.0$ & OPY-17 & 0 & 0 & 0 & 0 & 0 \\
\hline OPA-18 & 15 & 5 & 10 & $<0.5$ & $4.0-5.0$ & OPY-18 & 7 & 5 & 2 & $<0.5$ & $1.0-2.0$ \\
\hline OPA-19 & 7 & 2 & 5 & $<0.5$ & $1.0-2.0$ & OPY-19 & 9 & 1 & 8 & $<0.5$ & $2.0-3.0$ \\
\hline OPA-20 & 12 & 2 & 10 & $<0.5$ & $2.0-3.0$ & OPY-20 & 7 & 1 & 6 & $<0.5$ & $3.0-4.0$ \\
\hline
\end{tabular}

${ }^{\dagger} \mathrm{NAB}$ - Number of amplified bands

${ }^{\ddagger} \mathrm{NMB}$ - Number of monomorphic bands

${ }^{\S} \mathrm{NPB}$ - Number of polymorphic bands

Table 5. Number of bands and sizes of products generated by the ISSR primers.

\begin{tabular}{lccccc}
\hline \hline \multirow{2}{*}{ Primer name } & $\begin{array}{c}\text { Total number of ISSR } \\
\text { products per primer }\end{array}$ & Monomorphic bands & Polymorphic bands & \multicolumn{2}{c}{ Size (Kbp) of the product } \\
\cline { 3 - 6 } QBC-7 & 10 & 3 & 7 & Minimum & Maximum \\
QBC-8 & 7 & 3 & 4 & $0.5-1.0$ & $1.0-2.0$ \\
QBC-9 & 4 & 2 & 2 & $0.5-1.0$ & $1.0-2.0$ \\
QBC-10 & 11 & 5 & 6 & $<0.5$ & $1.0-2.0$ \\
QBC-14 & 10 & 2 & 8 & $<0.5$ & $1.0-2.0$ \\
QBC-15 & 9 & 3 & 6 & $<0.5$ & $1.0-2.0$ \\
QBC-17 & 12 & 1 & 11 & $0.5-1.0$ & $1.0-2.0$ \\
QBC-20 & 10 & 6 & 4 & $<0.5$ & $2.0-3.0$ \\
QBC-24 & 10 & 4 & 6 & $<0.5$ & $2.0-3.0$ \\
QBC-25 & 6 & 1 & 5 & $0.5-1.0$ & $2.0-3.0$ \\
\hline
\end{tabular}


Korean J. Plant Res. 24(6) : 675 687 (2011)

Table 6. The multiplex ratio, cophenetic correlation, polymorphism exhibited by RAPD and ISSR fingerprinting.

\begin{tabular}{lccc}
\hline \hline Fingerprinting & Multiplex ratio & Cophenetic correlation value $(\mathrm{r})$ & \% polymorphisms \\
\hline RAPD & 9.63 & 0.84 & $64.48 \%$ \\
ISSR & 8.9 & 0.72 & $66.29 \%$ \\
RAPD + ISSR & 9.48 & 0.80 & $64.84 \%$ \\
\hline
\end{tabular}

Table 7. Polymorphic index values obtained for RAPD and ISSR primers.

\begin{tabular}{|c|c|c|c|c|c|}
\hline Primer name & PIC & Primer name & PIC & Primer name & PIC \\
\hline OPA-01 & 0.202 & OPA-18 & 0.248 & OPY-15 & 0.272 \\
\hline OPA-02 & 0.260 & OPA-19 & 0.257 & OPY-16 & 0.230 \\
\hline OPA-03 & 0.267 & OPA-20 & 0.217 & OPY-17 & 0 \\
\hline OPA-04 & 0.303 & OPY-01 & 0.159 & OPY-18 & 0.113 \\
\hline OPA-05 & 0.165 & OPY-02 & 0.100 & OPY-19 & 0.247 \\
\hline OPA-06 & 0.180 & OPY-03 & 0.112 & OPY-20 & 0.178 \\
\hline OPA-07 & 0.271 & OPY-04 & 0.097 & UBC-07 & 0.127 \\
\hline OPA-08 & 0.302 & OPY-05 & 0.198 & UBC-08 & 0.085 \\
\hline OPA-09 & 0.215 & OPY-06 & 0.103 & UBC-09 & 0.122 \\
\hline OPA-10 & 0.240 & OPY-07 & 0.146 & UBC-10 & 0.192 \\
\hline OPA-11 & 0.078 & OPY-08 & 0.180 & UBC-14 & 0.306 \\
\hline OPA-12 & 0.145 & OPY-09 & 0.218 & UBC-15 & 0.272 \\
\hline OPA-13 & 0.224 & OPY-10 & 0.198 & UBC-17 & 0.300 \\
\hline OPA-14 & 0.243 & OPY-11 & 0.155 & UBC-20 & 0.248 \\
\hline OPA-15 & 0.270 & OPY-12 & 0 & UBC-24 & 0.304 \\
\hline OPA-16 & 0.268 & OPY-13 & 0.312 & UBC-25 & 0.264 \\
\hline OPA-17 & 0.158 & OPY-14 & 0.230 & & \\
\hline
\end{tabular}

information content of the markers. The multiplex ratios for the markers were found to be $9.63,8.9$, and 9.48 for the RAPD, ISSR, and RAPD + ISSR markers, respectively. The polymorphic index (PIC) was calculated individually for each marker and was between 0.097 and 0.312 , as shown in Table 7. The primers OPA-04, OPA-08, OPY-13, UBC-17, and UBC-24 produced maximum PIC values, which suggests that these primers can be used to discriminate among mulberry genotypes.

\section{Genetic dissimilarity among the genotypes}

The genetic dissimilarity coefficients were estimated individually for RAPD and ISSR markers, as well as for the combined RAPD and ISSR marker, using the Nei method. The results obtained for the RAPD markers had a dissimilarity coefficient varying from 0.141 to 0.265 . The maximum dissimilarity coefficients were found between Sekang and
Hwanggum, Suwonsang1ho and Hwanggum, followed by the Baeksaang and Hwanggum cultivars. The minimum dissimilarity coefficient of 0.141 was observed between the Sekang and Ilbongum, Mosam and Hyunsang, while Ilbongum and Jakchunil cultivars had a dissimilarity coefficient of 0.146. The Hwanggum cultivar had highest dissimilarity coefficients with remaining 13 genotypes, as presented in Table 8.

The dissimilarity coefficients calculated from ISSR markers ranged between 0.293 and 0.076. The Gakyongsang and Hwanggum cultivars had the highest dissimilarity coefficient of 0.293 , followed by the Gakyongsang and Hyangsang cultivars with 0.266 . The dissimilarity coefficients calculated for the ISSR marker are given in Table 9. The Jakchunil and Jungko cultivars were closely related to each other and had the lowest dissimilarity coefficient of 0.076 , while the Hosam cultivar was also found to be similar to Jungko, having a 0.091 
Table 8. Distance matrix values among 14 mulberry genotypes based on RAPD markers.

\begin{tabular}{|c|c|c|c|c|c|c|c|c|c|c|c|c|c|c|}
\hline & M1 & M2 & M3 & M4 & M5 & M6 & M7 & M8 & M9 & M10 & M11 & M12 & M13 & M14 \\
\hline M1 & 0.000 & & & & & & & & & & & & & \\
\hline M2 & 0.180 & 0.000 & & & & & & & & & & & & \\
\hline M3 & 0.189 & 0.225 & 0.000 & & & & & & & & & & & \\
\hline M4 & 0.177 & 0.219 & 0.200 & 0.000 & & & & & & & & & & \\
\hline M5 & 0.173 & 0.187 & 0.229 & 0.159 & 0.000 & & & & & & & & & \\
\hline M6 & 0.173 & 0.198 & 0.202 & 0.190 & 0.175 & 0.000 & & & & & & & & \\
\hline M7 & 0.249 & 0.263 & 0.236 & 0.235 & 0.265 & 0.224 & 0.000 & & & & & & & \\
\hline M8 & 0.168 & 0.182 & 0.261 & 0.174 & 0.141 & 0.166 & 0.230 & 0.000 & & & & & & \\
\hline M9 & 0.168 & 0.177 & 0.244 & 0.190 & 0.161 & 0.176 & 0.246 & 0.157 & 0.000 & & & & & \\
\hline M10 & 0.186 & 0.239 & 0.259 & 0.219 & 0.192 & 0.198 & 0.233 & 0.198 & 0.187 & 0.000 & & & & \\
\hline M11 & 0.161 & 0.175 & 0.184 & 0.178 & 0.159 & 0.179 & 0.238 & 0.175 & 0.141 & 0.196 & 0.000 & & & \\
\hline M12 & 0.174 & 0.182 & 0.235 & 0.180 & 0.150 & 0.165 & 0.232 & 0.176 & 0.192 & 0.199 & 0.169 & 0.000 & & \\
\hline M13 & 0.171 & 0.211 & 0.215 & 0.193 & 0.184 & 0.195 & 0.225 & 0.146 & 0.201 & 0.211 & 0.169 & 0.179 & 0.000 & \\
\hline M14 & 0.194 & 0.191 & 0.211 & 0.210 & 0.173 & 0.179 & 0.190 & 0.168 & 0.216 & 0.230 & 0.172 & 0.179 & 0.172 & 0.000 \\
\hline
\end{tabular}

Table 9. Distance matrix values among 14 mulberry genotypes based on ISSR markers.

\begin{tabular}{|c|c|c|c|c|c|c|c|c|c|c|c|c|c|c|}
\hline & M1 & M2 & M3 & M4 & M5 & M6 & M7 & M8 & M9 & M10 & M11 & M12 & M13 & M14 \\
\hline M1 & 0.000 & & & & & & & & & & & & & \\
\hline M2 & 0.178 & 0.000 & & & & & & & & & & & & \\
\hline M3 & 0.186 & 0.106 & 0.000 & & & & & & & & & & & \\
\hline M4 & 0.186 & 0.195 & 0.145 & 0.000 & & & & & & & & & & \\
\hline M5 & 0.169 & 0.198 & 0.205 & 0.186 & 0.000 & & & & & & & & & \\
\hline M6 & 0.139 & 0.134 & 0.159 & 0.156 & 0.139 & 0.000 & & & & & & & & \\
\hline M7 & 0.232 & 0.178 & 0.186 & 0.293 & 0.254 & 0.218 & 0.000 & & & & & & & \\
\hline M8 & 0.210 & 0.218 & 0.205 & 0.165 & 0.232 & 0.121 & 0.189 & 0.000 & & & & & & \\
\hline M9 & 0.146 & 0.175 & 0.164 & 0.182 & 0.186 & 0.156 & 0.186 & 0.186 & 0.000 & & & & & \\
\hline M10 & 0.186 & 0.156 & 0.164 & 0.223 & 0.186 & 0.195 & 0.186 & 0.206 & 0.105 & 0.000 & & & & \\
\hline M11 & 0.186 & 0.195 & 0.164 & 0.266 & 0.249 & 0.215 & 0.165 & 0.227 & 0.182 & 0.163 & 0.000 & & & \\
\hline M12 & 0.178 & 0.189 & 0.141 & 0.215 & 0.178 & 0.152 & 0.218 & 0.218 & 0.175 & 0.156 & 0.138 & 0.000 & & \\
\hline M13 & 0.206 & 0.195 & 0.145 & 0.163 & 0.186 & 0.175 & 0.186 & 0.206 & 0.124 & 0.143 & 0.182 & 0.101 & 0.000 & \\
\hline M14 & 0.151 & 0.162 & 0.133 & 0.148 & 0.190 & 0.144 & 0.210 & 0.190 & 0.148 & 0.130 & 0.187 & 0.091 & 0.076 & 0.000 \\
\hline
\end{tabular}

dissimilarity coefficient. The dissimilarity matrix was also constructed by combining the data from both the RAPD and ISSR markers, which is presented in Table 10. The combined analysis of both the markers revealed that Sekang and Hwanggum cultivars had the highest dissimilarity coefficient, followed by those of the Suwansang1ho and Ilbongum, and the Suwon and Hwanggum cultivars. The dissimilarity coefficients were between 0.263 and 0.149 , with the lowest value of
0.149 occurring between Mosam and Hyangsang cultivars, followed by those of the Jakchunil and Jungko, Guksang70ho and Ilbongun, and Sekang and Hosam cultivars.

\section{Cluster analysis of the genotypes}

The dendrograms were generated from RAPD, ISSR, and RAPD+ISSR fingerprinting using UPGMA analysis and are presented in Figs. 1, 2, and 3, respectively. The dendrogram 
Table 10. Distance matrix values among 14 mulberry genotypes based on combined RAPD and ISSR markers.

\begin{tabular}{|c|c|c|c|c|c|c|c|c|c|c|c|c|c|c|}
\hline & M1 & M2 & M3 & "M4 & M5 & M6 & M7 & M8 & M9 & M10 & M11 & M12 & M13 & "M14 \\
\hline M1 & 0.000 & & & & & & & & & & & & & \\
\hline M2 & 0.180 & 0.000 & & & & & & & & & & & & \\
\hline M3 & 0.189 & 0.197 & 0.000 & & & & & & & & & & & \\
\hline M4 & 0.179 & 0.214 & 0.188 & 0.000 & & & & & & & & & & \\
\hline M5 & 0.172 & 0.190 & 0.224 & 0.164 & 0.000 & & & & & & & & & \\
\hline M6 & 0.166 & 0.183 & 0.192 & 0.183 & 0.168 & 0.000 & & & & & & & & \\
\hline M7 & 0.246 & 0.244 & 0.225 & 0.247 & 0.263 & 0.223 & 0.000 & & & & & & & \\
\hline M8 & 0.177 & 0.190 & 0.250 & 0.173 & 0.158 & 0.156 & 0.221 & 0.000 & & & & & & \\
\hline M9 & 0.164 & 0.177 & 0.227 & 0.189 & 0.166 & 0.172 & 0.233 & 0.163 & 0.000 & & & & & \\
\hline M10 & 0.186 & 0.220 & 0.238 & 0.220 & 0.191 & 0.197 & 0.223 & 0.200 & 0.170 & 0.000 & & & & \\
\hline M11 & 0.166 & 0.179 & 0.180 & 0.195 & 0.176 & 0.187 & 0.223 & 0.185 & 0.149 & 0.189 & 0.000 & & & \\
\hline M12 & 0.175 & 0.184 & 0.214 & 0.187 & 0.156 & 0.162 & 0.229 & 0.185 & 0.189 & 0.189 & 0.163 & 0.000 & & \\
\hline M13 & 0.178 & 0.208 & 0.201 & 0.187 & 0.185 & 0.191 & 0.217 & 0.158 & 0.185 & 0.197 & 0.172 & 0.163 & 0.000 & \\
\hline M14 & 0.184 & 0.184 & 0.193 & 0.196 & 0.177 & 0.171 & 0.194 & 0.173 & 0.202 & 0.207 & 0.175 & 0.159 & 0.152 & 0.000 \\
\hline
\end{tabular}

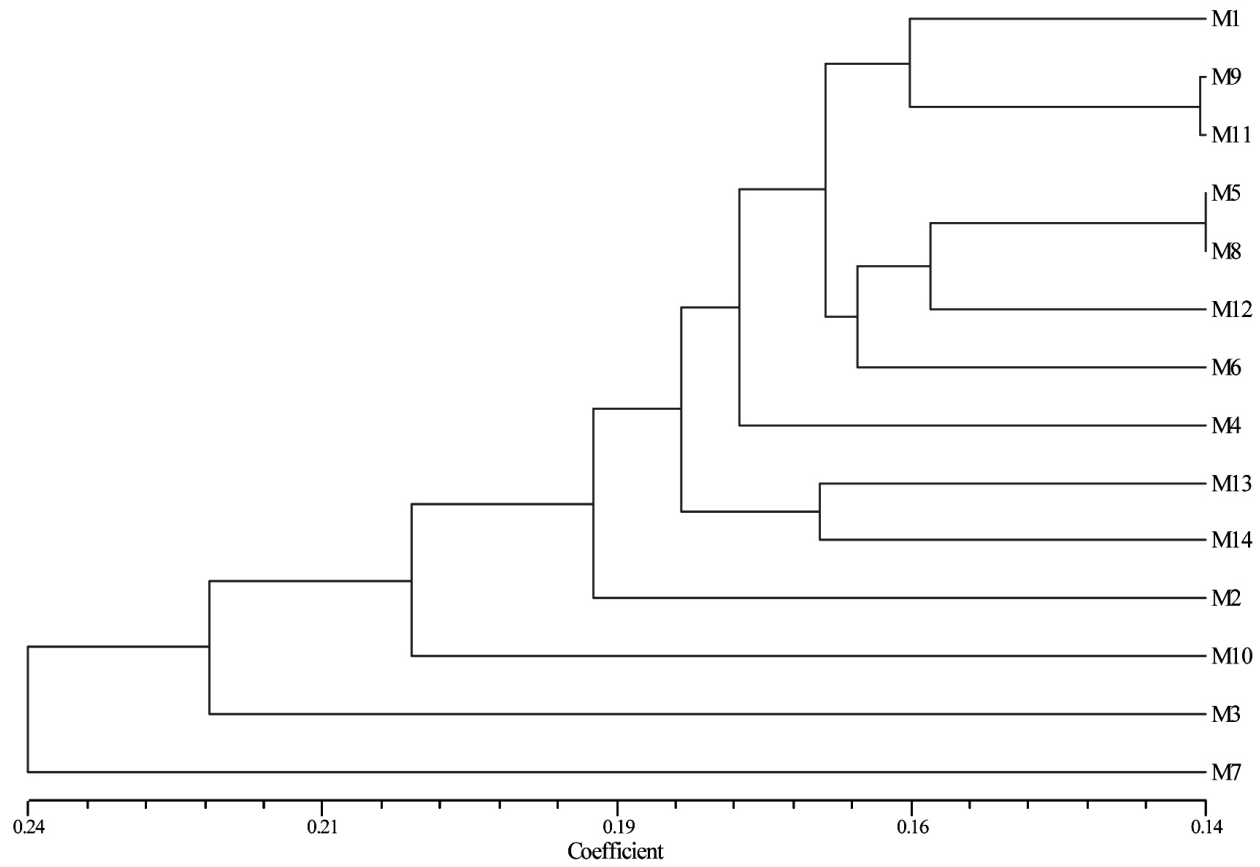

M1-Suwon, M2-Baeksaang, M3-Suwonsang1ho, M4-Gakyongsang, M5-Sekang, M6-Guksang70ho, M7-Hwanggum, M8-Ilbongum, M9-Mosam, M10-Jeonwon2ho, M11-Hyangsang, M12-Hosam, M13-Jakchunil, M14-Jungko.

Fig. 1. Dendrogram obtained from RAPD fingerprinting using UPGMA analysis for 14 mulberry genotypes.

obtained via RAPD fingerprinting divided the 14 genotypes into seven clusters of Suwon, Mosam, Hyangsang, Sekang, Ilbongum, Hosam, and Guksang70ho. The other genotypes, Gakyongsang, Baeksang, Jeonwon2ho, Suwonsang1ho and Hwangum, formed individual clusters, with the Jakchunil and Jungko cultivars forming one separate cluster. The dendrogram obtained from the ISSR fingerprinting broadly separates the 14 genotypes into three clusters. The first group consists of Hwanggum and Hyangsang, and the second group included Suwon and Sekang. The third and the largest group contained the Baeksaang, Suwonsang1ho, Mosam, Jeonwon2ho, Hosam, Jakchunil, Jungko, Gakyongsang, Guksang70ho, and Ilbongum 


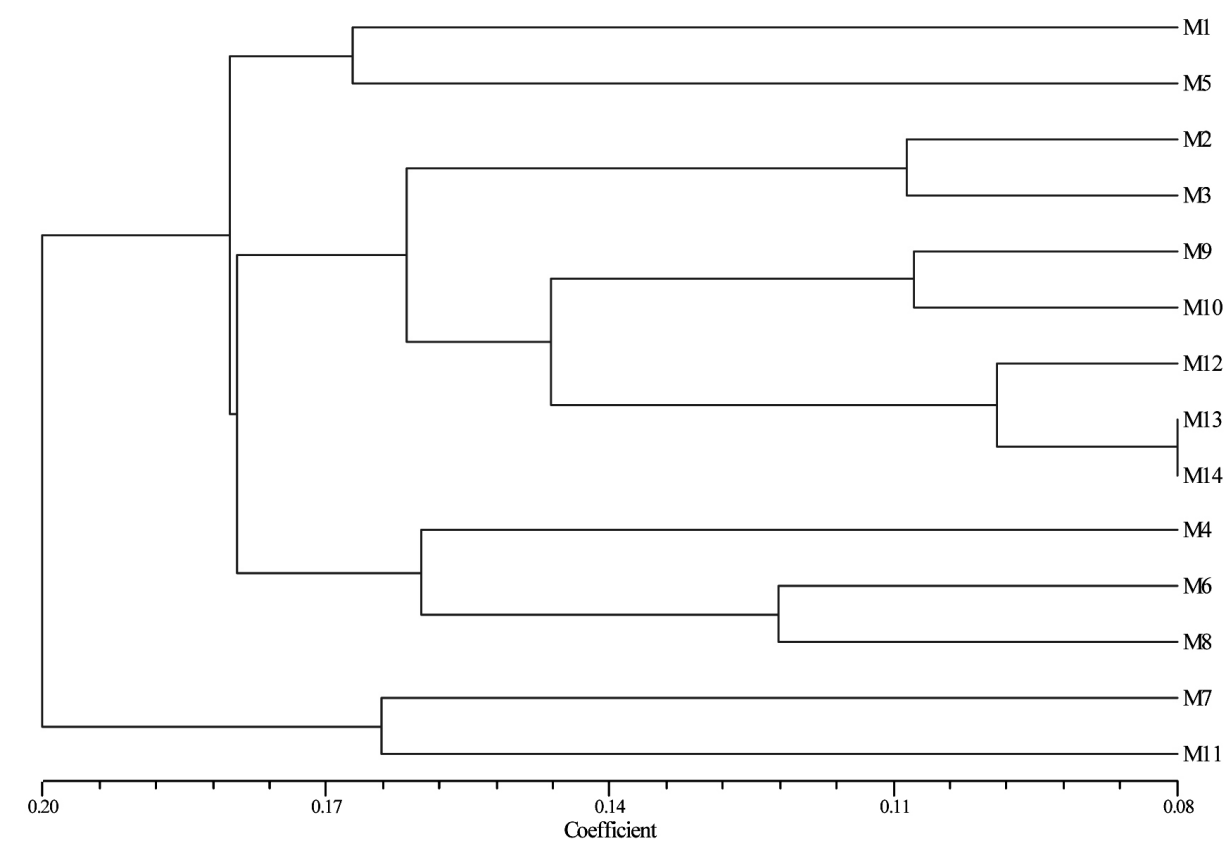

M1-Suwon, M2-Baeksaang, M3-Suwonsang1ho, M4-Gakyongsang, M5-Sekang, M6-Guksang70 ho, M7-Hwanggum, M8-Ilbongum, M9-Mosam, M10-Jeonwon2ho, M11-Hyangsang, M12- Hosam, M13-Jakchunil, M14-Jungko.

Fig. 2. Dendrogram obtained from ISSR fingerprinting using UPGMA analysis for 14 mulberry genotypes.

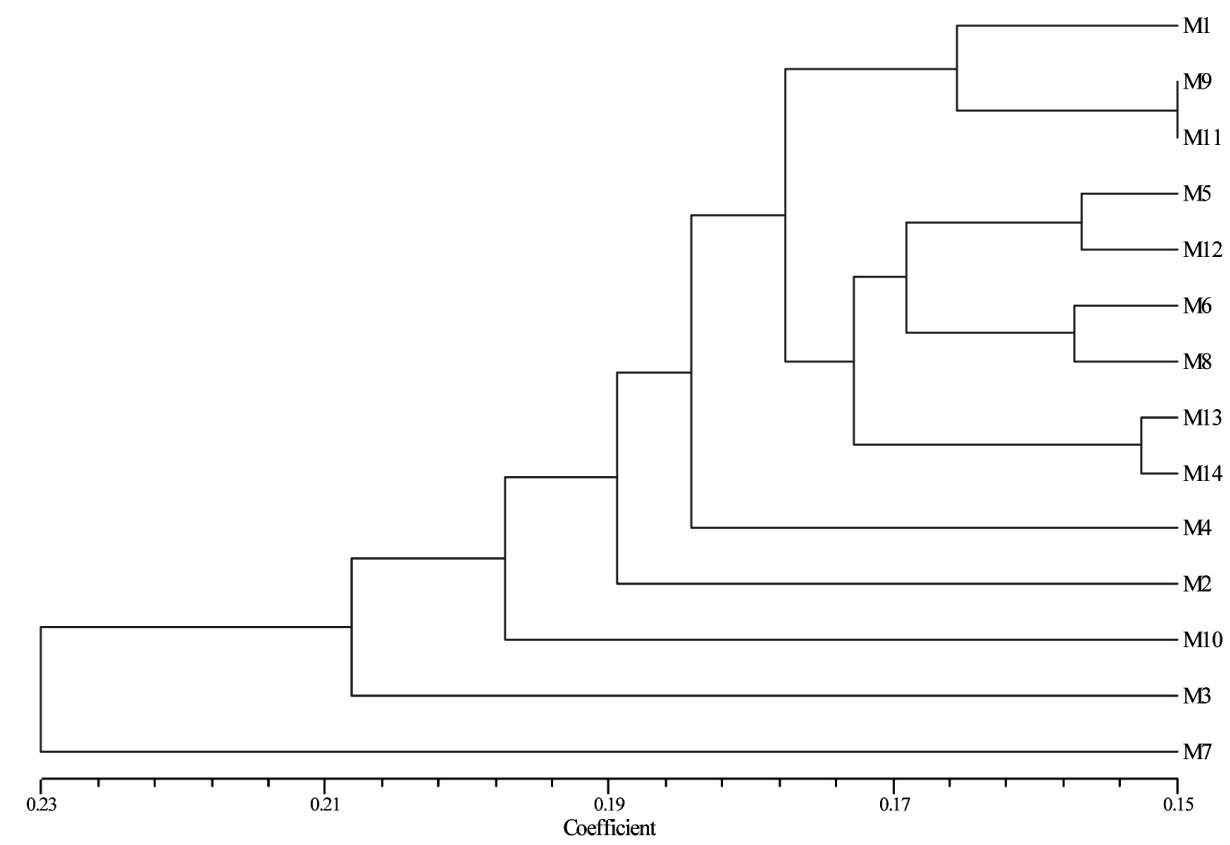

M1-Suwon, M2-Baeksaang, M3-Suwonsang1 ho, M4-Gakyongsang, M5-Sekang, M6-Guksang 70 ho, M7-Hwanggum, M8-Ilbongum, M9-Mosam, M10-Jeonwon2ho, M11-Hyangsang, M12-Hosam, M13-Jakchunil, M14-Jungko.

Fig. 3. Dendrogram obtained from pooled RAPD and ISSR fingerprinting using UPGMA analysis for 14 mulberry genotypes.

cultivars.

The dendrogram from the pooled RAPD and ISSR markers had seven clusters. The Hwanggam and Suwonsang1ho,
Jeonwon2ho, Baeksaang, Gakyongsang cultivars remained in separate clades. The Sekang, Hosam, Guksang70ho, Ilbongum, Jakchunil, and Jungko cultivars were closely related to each 


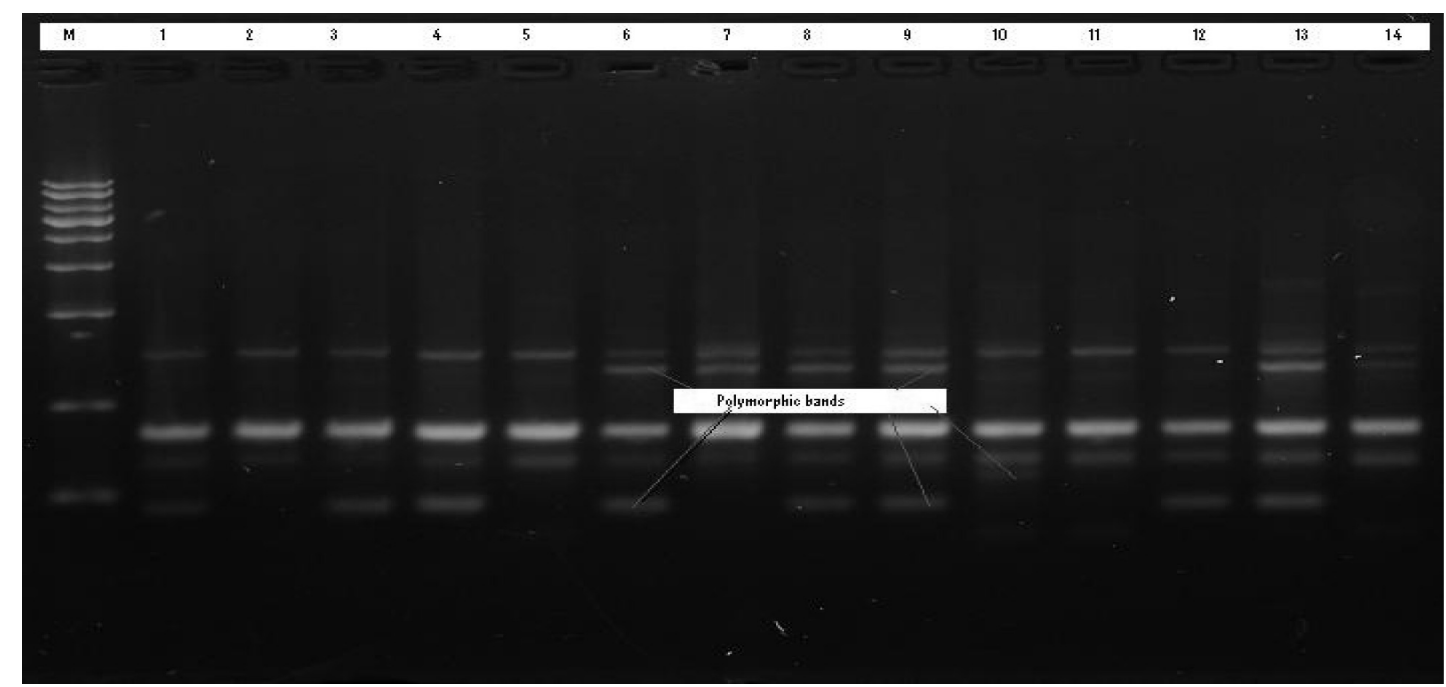

Fig. 4. RAPD fingerprint of 28 mulberry varieties generated by the OPY-1 primer, where M- molecular marker, 1-Suwon, 2-Baeksaang, 3-Suwonsang1ho, 4-Gakyongsang, 5-Sekang, 6-Guksang70ho, 7-Hwanggum, 8-Ilbongum, 9-Mosam, 10Jeonwon2ho, 11-Hyangsang, 12-Hosam, 13-Jakchunil, 14-Jungko.

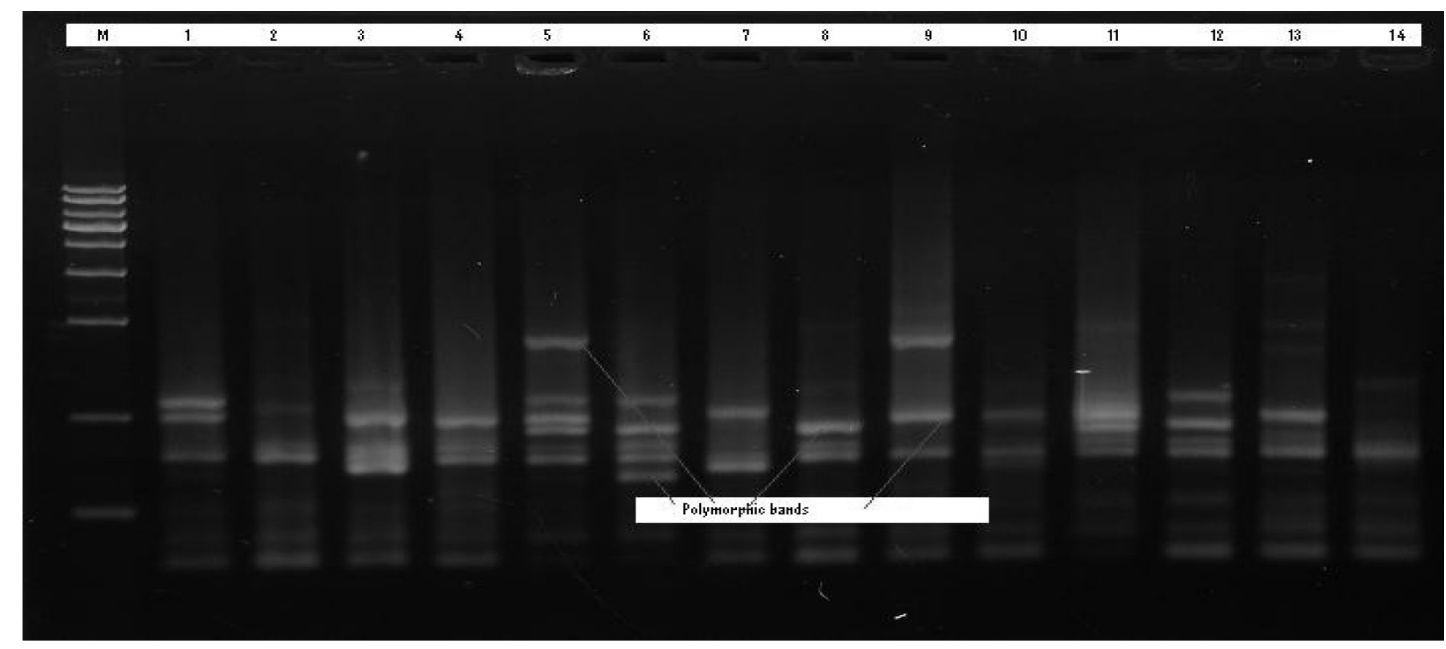

Fig. 5. ISSR fingerprint of 28 mulberry varieties generated by the UBC-15 primer, where M-molecular marker, 1-Suwon, 2-Baeksaang, 3-Suwonsang1ho, 4-Gakyongsang, 5-Sekang, 6-Guksang70ho, 7-Hwanggum, 8-Ilbongum, 9-Mosam, 10Jeonwon2ho, 11-Hyangsang, 12-Hosam, 13-Jakchunil, 14-Jungko.

other and formed a separate group. The Suwon, Mosam, and Hyangsang were separated into another group where the Mosam and Hyansang were similar to each other. From all three dendrograms obtained, it was clear that the Jakchunil and Jungko cultivars were closely related to each other, while the Suwon and Hwanggum cultivars were more distantly related.

The Hwanggum which differed greatly in their morphological characters among the fourteen cultivars also differed at the genome level. They formed separate clade in both RAPD and ISSR fingerprinting. The cultivars Jakchunil and Jungko were found to be very closely related as by the ISSR fingerprinting and closer with RAPD fingerprinting. In the combined dendrogram constructed using RAPD and ISSR fingerprinting also revealed that Jakchunil and Jungko were closely related, they could have arised from parents of similar genome, but the analysis of their parents could not be done as the origin and pedigree of these samples were unknown. The genotypes 
Suwon and Suwonsang1ho had similar leaf morphology but they vary much between them at their genetic level. The Mosam and Hyangsang are found to be closely related as by the RAPD fingerprinting, but distantly related with each other as revealed by ISSR fingerprinting, so further analysis are required to make their relationship clear. One of the disadvantages of fingerprinting is that, analysis is performed based on the band pattern, and this band pattern in turn is generated based on the length of base pairs but not on the sequence.

The interactions of different processes, such as the longterm evolutionary history of populations including shifts in distribution, habitat fragmentation, and population isolation, mutation, genetic drift, mating system, gene flow and selection are reflected through the genetic structure of the plant (Zhao et al., 2007). According to Bhat et al.(1999), the extent of distribution, sampling area, and plant characteristics such as reproduction, breeding behavior, and generation time are some of the important parameters which illustrate the level of genetic variability revealed in a taxon. The RAPD and ISSR analyses were selected as they are very simple and costeffective methods and because these two markers amplify different regions of the genome in order to measure genetic variability of the plants. It was obvious that the dendrogram generated using RAPD and ISSR markers were different because the regions amplified by the markers were different. Similar results have been reported in earlier studies with Jatropa curcas and mulberry (Gupta et al., 2008; Vijayan et al., 2004). The genetic diversity in the cultivars of the mulberry may be due to any of one or more of the combinations of natural mutations, cross-pollination, and propagation techniques (Ozrenk et al., 2010). Previous studies have shown that the greater genetic diversity present among the cultivated forms was due to free natural hybridizations (Vijayan and Chatterjee, 2003; Vijayan, 2004; Vijayan et al., 2004). The isozymes and sap protein analysis did not differentiate significant differences between mulberries (Hirano, 1980). Previous studies using RAPD, ISSR, and AFLP molecular markers demonstrated the genetic differences among the species and genotypes (Sharma et al., 2000; Aswathi et al., 2004; Vijayan et al., 2006; Orhan et al., 2007; Zhao et al., 2007). The results of our RAPD and ISSR fingerprinting reveal wide variation among the 14 genotypes, which reflects high polymorphism at the DNA level.

To verify the robustness of the dendrogram, the cophenetic correlation coefficient was calculated for RAPD, ISSR, and RAPD + ISSR markers. First, the cophenetic matrix was constructed; then, using genetic dissimilarity matrix and cophenetic matrix, the cophenetic correlation was calculated. The cophenetic correlation coefficients (r) for the RAPD, ISSR, and RAPD + ISSR markers were $0.84,0.72$, and 0.80 , respectively, which were also found to be significant.

The results of this study are very important for detecting diversity among genotypes. The current use of the RAPD and ISSR markers also provides a clear picture of the genetic relationships among the genotypes. The results of the polymorphism rate and the polymorphic index also provide information about the primers, which can be utilized for further studies of the diversity among closely-related mulberry cultivars. The results of this study can be utilized for breeding programs to develop good, fertile, and resistant varieties.

\section{Acknowledgement}

This research was supported by the Korea Forest Service, Grant No. S-121010L130120.

\section{Literature Cited}

Ammiraju, J.S.S., B.B. Dholakia, D.K. Santra, H. Singh, M.D Lagu, S.A. Tamhankar, H.S. Dhaliwal, V.S. Rao, V.S. Gupta and P.K. Ranjekar. 2001. Identification of inter simple sequence repeat (ISSR) markers associated with seed size in wheat. Theor. Appl. Genet. 102:726-732.

Awasthi, A.K., G.M. Nagaraja, G.V. Naik, K. Sriramana, K. Thangavelu and N. Javaregowda. 2004. Genetic diversity and relationships in mulberry (genus Morus) as revealed by RAPD and ISSR marker assays. BMC Genet. 5:1.

Bhat, K.V., P.P. Babrekar and S. Lakhanpaul. 1999. Study of genetic diversity in Indian and exotic sesame (Sesamum indicum L.) germplasm using random amplified polymorphic DNA (RAPD). Euphytica 110:21-33.

Bhattacharya, E., and S.A. Ranade. 2001. Molecular distinction amongst varieties of mulberry using RAPD and DAMD 
profiles. BMC Plant Biol. 1:3.

Blair, M.W., O. Panaud and S.R. McCouch. 1999. Inter-simple sequence repeat (ISSR) amplification for analysis of microsatellite motif frequency and finger printing in rice (Oryza sativa L.). Theor. Appl. Genet. 98:780-792.

Bornet, B and M. Branchard. 2001. Nonanchored Inter Simple Sequence Repeat (ISSR) markers: reproducible and specific tools for genome fingerprinting, Plant Mol. Biol. Rep. 19:209-215.

Charters, Y.M., A. Robertson, M.J. Wilkinson and G. Ramsay. 1996. PCR analysis of oilseed rape cultivars using 5'anchored SSR primers. Theor. Appl. Genet. 84:442-447.

Doyle, J.J. and J.L. Doyle. 1987. A rapid DNA isolation procedure for small quantities of fresh leaf tissue. Phytochem. Bull. 19:11-15.

Deepmala, S. and S.M. Raina. 2005. Genotyping safflower (Carthamus tictorius) cultivars by DNA fingerprints. Euphytica 146:67-76.

Fang, D.Q. and M.L. Rose. 1997. Identification of closely related citrus cultivars with ISSR markers. Theor. Appl. Genet. 95:498-517.

Fotedar, R.K. and S.B. Dandin. 1998. Genetic divergence in the mulberry. Sericologia 38:115-125.

Ghislain, M., D. Zhang, D. Fajardo, Z. Huamann and R.H. Hijmans. 1999. Marker-assisted sampling of the cultivated Andean potato Solanum phureja collection using RAPD markers. Genet. Resour. Crop Ev. 46:547-555.

Gupta, S., Mani Srivastava, G.P. Mishra, P.K. Naikl, R.S. Chauhanl, S.K. Tiwari, Meetul Kumar and Raghwendra Singh. 2008. Analogy of ISSR and RAPD markers for comparative analysis of genetic diversity among different Jatropha curcas genotypes. Afr. J. Biotechnol. 7(23): 4230-4243.

Hirano, H. 1980. Thremmetological studies of protein variation in mulberry. Bull. Seric. Exp. Sta. 28:67-186.

Hirana, H. 1982. Varietal differences of leaf protein profiles in mulberry. Phytochemestry 21:1513-1518.

Hotta, T. 1954. Taxonomical study on cultivated mulberry in Japan. Botanical Institute, Faculty of Textile fibers, Kyoto University of Industrial Arts and Textile Fibers, Japan.

Kantety, R.V., X. Zeng, J.L. Bennetzen and B.E Zehr. 1995. Assessment of genetic diversity in dent and popcorn (Zea mays L.) inbred lines using inter-simple sequence repeat (ISSR) amplification. Mol. Breed. 1:365-373.

Katsumata, F. 1972. Mulberry species in South Vietnam. J.
Seric. Japan. 42:84-88.

Koidzumi, G. 1917. Taxonomy and phytogeography of the genus Morus. Bull. Seric. Exp. Station, Tokyo, Japan.

Mala, V.R., H.K. Chaturvedi and A. Sarkar. 1997. Multivariate analysis as an aid to accession selection for breeding in mulberry. Indian J. Seric. 36:111-115.

Mantel, N. 1967. The detection of disease clustering and a generalized regression approach. Cancer Res. 27:175-178.

Nei, M. (1972). Genetic distance between populations. American Nat. 106: 283-292.

Ozrenk, K., R.I. Gazioglu Sensoy, C. Erdinc, M. Guleryuz and A. Aynkanat. 2010. Molecular characterization of mulberry germplasm from Eastern Anatolia. Afr. J. Biotechnol. 9(1):1-6.

Orhan, E., S. Ercisli, N. Yildirim and G. Agar. 2007. Genetic variations among mulberry genotypes (Morus alba) as revealed by Random Amplified Polymorphic DNA (RAPD) markers. Plant Syst. Evol. 265:251-258.

Powell, W., M. Morgante, C. Andre, M. Hanafey, J. Vogel, S. Tingey and A. Rafalski. 1996 The comparison of RFLP, RAPD, AFLP and ISSR (microsatellite) marker for germplasm analysis. Mol. Breed. 2:225-238.

Prevost, A. and M.J. Wilkinson. 1999. A new system of comparing PCR primers applied to ISSR fingerprinting of potato cultivars. Theor. Appl. Genet. 98:107-112.

Sastry, C.R. 1984. Mulberry varieties, exploitation and pathology. Sericologia 24:449-461.

Sharma, A., R. Sharma, and H. Machii. 2000. Assessment of genetic diversity in a Morus germplasm collection using fluorescence-based AFLP markers. Theor. Appl. Genet. 101:1049-1055.

Smith, J.S.C., E.C.L. Chin, H. Shu, O.S. Smith, S.J. Wall, M.L. Senior, S.E. Mitchel, S. Kresorich and J. Tiegle. 1997. An evaluation of the utility of SSR loci as molecular markers in maize (Zea mays): comparisons with data from RFLP and pedigree. Theor. Appl. Genet. 95:163-173.

Srivastava, P.P., K. Vijayan, A. K. Awasthi and B. Saratchandra. 2004. Genetic analysis of Morus alba through RAPD and ISSR markers. Indian J. Biotechnol. 3:527-532.

Vijayan, K., K.K. Das, S.G. Doss, S.P. Chakaborti and B.N. Roy. 1999. Genetic divergence in indigeneous mulberry (Morus spp.) accessions. Indian J. Agr. Sci. 69:851-853.

Vijayan, K. 2003. Genetic relationships of Japanese and Indian mulberry (Morus spp.) genotypes revealed by DNA fingerprinting. Plant Syst. Evol. DOI 10.1007/s00606- 
003-0078-y.

Vijayan, K. and S.N. Chatterjee. 2003. ISSR profiling of Indian cultivars of mulberry (Morus spp.) and its relevance to breeding programs. Euphytica 131:53-63.

Vijayan, K., P.P. Srivastava and A.K. Awasthi. 2003. Analysis of phylogenetic relationship among five mulberry (Morus) species using molecular markers. Genome 47:439-448.

Vijayan, K., A.K. Awasthi, P.P. Srivastava and B. Saratchandra. 2004. Genetic analysis of Indian mulberry varieties through molecular markers. Hereditas 141:8-14.

Vijayan, K., A. Tikader, P.K. Kar, P.P. Srivastava, A.K. Awasthi, K. Thangavelu and B. Saratchandra. 2006. Assessment of genetic relationships between wild and cultivated mulberry (Morus) species using PCR based markers. Genetic Res. Crop Evol. 53:873-882.

Welsh, J., and M. McClelland. 1990. Fingerprinting genome using PCR with arbitrary primers. Nucleic Acids Res. 189:7213-7218.

Williams, J.G.K., A.R. Kubelik, K.J. Livak, J.A. Rafalski and S.V. Tingey. 1990. DNA polymorphisms amplified by arbitrary primers are useful as genetic markers. Nucleic Acids Res. 18:6531-6535.
Wu, K. and S.D. Tanksley. 1993. Abundance, polymorphism and genetic mapping of microsatellites in rice. Mol. Gen. Genet. 241:225-235.

Yonemoto, Y., A.K. Chowdhury, H. Kato and M.M. Macha. 2006. Cultivars identification and their genetic relationships in Dimocarpus longan subspecies based on RAPD markers. Sci. Hortic-Amsterdam 109:147-152.

Zhao, W., Y. Wang, T. Chen, G. Jia, X. Wang, J. Qi, Y. Pang, S. Wang, Z. Li, Y. Huang, Y. pan and Y.H. Yang. 2007. Genetic structure of mulberry from different ecotypes revealed by ISSRs in China: An implications for conservation of local mulberry varieties. Sci. Horti-Amsterdam 11: 47-55.

Zhao, W.G., C. Tingting, Y. Yonghua and P.Y. Le. 2007. A preliminary analysis of asexual genetic variability in mulberry as revealed by ISSR markers. Int. J. Agric. Biol. $9(6): 928-930$.

Zietkiewicz, E., A. Rafalski and D. Labuda. 1994. Genome fingerprinting by simple sequence repeat (ISSR) - anchored polymerase chain reaction amplification. Genomics 20: 176-183.

(Received 21 January 2011 ; Revised 12 August 2011 ; Accepted 18 November 2011) 